Article

\title{
Electric Circuit Model for the Aerodynamic Performance Analysis of a Three-Blade Darrieus-Type Vertical Axis Wind Turbine: The Tchakoua Model
}

\author{
Pierre Tchakoua ${ }^{1,2, *}$, René Wamkeue ${ }^{1,2}$, Mohand Ouhrouche ${ }^{1}$, Ernesto Benini ${ }^{3}$ and \\ Gabriel Ekemb 1,2 \\ 1 Department of Applied Sciences, University of Québec at Chicoutimi, 555 Boulevard de l'Université, \\ Chicoutimi, QC G7H 2B1, Canada; rene.wamkeue@uqat.ca (R.W.); mohand_ouhrouche@uqac.ca (M.O.); \\ gabriel.ekemb@uqac.ca (G.E.) \\ 2 School of Engineering, University of Québec in Abitibi-Témiscamingue (UQAT), \\ 445 Boulevard de l'Université, Rouyn-Noranda, QC J9X 5E4, Canada \\ 3 Department of Industrial Engineering of the University of Padua, Via Venezia 1, Padua 35131, Italy; \\ ernesto.benini@unipd.it \\ * Correspondence: pierre.tchakoua-takoutsing@uqat.ca; Tel.: +1-819-762-0971 (ext. 4382); Fax: +1-819-797-4727
}

Academic Editor: Frede Blaabjerg

Received: 24 July 2016; Accepted: 30 September 2016; Published: 14 October 2016

\begin{abstract}
The complex and unsteady aerodynamics of vertical axis wind turbines (VAWTs) pose significant challenges for simulation tools. Recently, significant research efforts have focused on the development of new methods for analysing and optimising the aerodynamic performance of VAWTs. This paper presents an electric circuit model for Darrieus-type vertical axis wind turbine (DT-VAWT) rotors. The novel Tchakoua model is based on the mechanical description given by the Paraschivoiu double-multiple streamtube model using a mechanical-electrical analogy. Model simulations were conducted using MATLAB for a three-bladed rotor architecture, characterized by a NACA0012 profile, an average Reynolds number of 40,000 for the blade and a tip speed ratio of 5 . The results obtained show strong agreement with findings from both aerodynamic and computational fluid dynamics (CFD) models in the literature.
\end{abstract}

Keywords: wind energy; Darrieus turbines; vertical axis wind turbine; modelling; electric circuit model; aerodynamic characteristics; performance analysis; Tchakoua model

\section{Introduction}

Darrieus-type vertical axis wind turbines (DT-VAWTs) are nonlinear systems that operate in turbulent environments. Therefore, it is difficult to accurately characterize their aerodynamic rotor behaviour across a wide range of operating conditions using physically meaningful models. Commonly used models are either derived from wind turbine data and are presented in a "black box" format or are computationally expensive. Indeed, most of these models lack both conciseness and intelligibility and are therefore prohibitive for the routine engineering analyses of the local interaction mechanisms of wind turbines. Furthermore, none of the models with high reliability and accuracy can be efficiently coupled with models of the other mechanical and electrical parts of the wind turbine to form a global model for the wind energy conversion system (WECS).

Models are of central importance in many scientific contexts and are one of the principal instruments of modern science. Scientists spend considerable time building, testing, comparing and revising models, and many scientific publications are dedicated to introducing, applying and interpreting these valuable tools. The use of electrical circuit elements to model physical devices and systems has a long and successful history. Additionally, understanding analogies and constructing 
an analogue model for a given system allows the system to be studied in an environment other than that for which it is intended [1-3], thereby facilitating the study of specific system phenomena. Moreover, a model based on electrical components is accessible and quickly understood by researchers from almost all engineering fields. This wide understanding is of great importance because research and development in the wind turbine industry requires competencies from several different fields of engineering. Furthermore, the equivalent electrical model can take advantage of existing resources by simultaneously capitalizing on the strengths of these resources and minimizing their respective drawbacks. In addition, such a model can be a good tool for simulating wind turbine rotor operation in the case of physical damage or structural faults on one or more blades. Finally, because electrical and other dynamic models for other parts of the wind turbine have been developed [4-11], this new rotor model can easily be linked to existing models to create an overall wind turbine model.

This paper presents an electric circuit model for three-blade DT-VAWT rotors that we named the Tchakoua model. This model is based on a recently developed approach for modelling DT-VAWT rotors using the equivalent electrical circuit analogy that is presented in [12-14]. The proposed model was built from the mechanical description given by the Paraschivoiu double-multiple streamtube model and was based on an analogy between mechanical and electrical circuits. Thus, the rotating blades and the blades' mechanical coupling to the shaft are modelled using the mechanical-electrical analogy, and the wind flow is modelled as a source of electric current.

This paper is organized as follows: Section 2 presents the context of the work and the methodology used for building the model; Section 3 presents the theoretical background and the model construction; the results are presented and discussed in Section 4; and Section 5 concludes the paper.

\section{Context and Method}

\subsection{Context}

Due to their compactness, adaptability for domestic installations, omni-directionality, and other advantages, VAWTs have recently become the focus of renewed interest. Several universities and research institutions have conducted extensive research and developed numerous designs based on aerodynamic computational models [15-17]. For example, the on-going studies at the University of Québec at Abiti-Témiscamingue could construct a new model that is more appropriate for the design and further conceptual analysis focusing on operational optimization, condition monitoring, and fault prediction and detection of DT-VAWT rotors. Figure 1 shows the "Cap d'Ours" three-blade VAWT that serves as a teaching and research tool at the University of Québec at Abitibi-Témiscamingue.

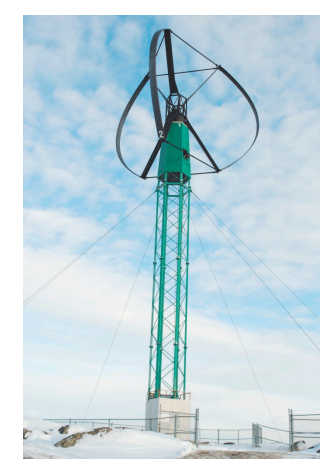

Figure 1. "Cap d'Ours wind turbine", a curved, three-blade, Darrieus-type VAWT.

Several advances have been made in the understanding and modelling of wind turbine aerodynamics. Various models for VAWT aerodynamic simulation can be found in the literature. These models can be broadly classified into four categories: momentum models, vortex models, cascade models and computational fluid dynamic (CFD) models. A literature survey on the most used models 
was conducted in $[12,14]$. Aerodynamics are still unable to meet the demands of various applications, although the streamtube and vortex models have seen significant improvements. However, as with all knowledge, our understanding of aerodynamics is not absolute and can be viewed as tentative, approximate, and always subject to revision. For instance, CFD solutions remain very computationally expensive and are prohibitive for routine engineering analyses of the local interaction mechanisms of wind turbines. Furthermore, none of the models with high reliability and accuracy can be efficiently coupled with the models of the other mechanical and electrical parts of the wind turbine to create a global model for the wind energy conversion system (WECS).

To overcome these problems, this paper presents a DT-VAWT model that is built using electric components. The Tchakoua model is a circuit-based model that is advantageous because it allows an electrical engineer to visualize and understand the working principles and the aerodynamics underlying the VAWT rotor functions and behaviour in a connected circuit better than a black box or a complex equation. Indeed, wind energy is a multidisciplinary domain with increasing research in the field of electrical engineering. Furthermore, the Tchakoua model could be linked to existing electric models of other mechanical and electrical parts of a wind turbine to form a global model for the WECS. Such a global circuit-based model for WECS will help users to understand the effects of various parameters on the aerodynamic blade forces and the effects of rotor structural faults on the overall WECS performance. According to [18-20], this model will contribute to constructing a global model that can be used to develop or improve the overall condition monitoring technique for WECS. Overall WTCM approaches include performance monitoring, power curve analysis, electrical signature, and supervisory control and data acquisition (SCADA) system data analysis. Compared to subsystem condition monitoring techniques, global system condition monitoring techniques are nonintrusive, low cost and reliable; global monitoring techniques can be used in online monitoring to reduce downtime and OM costs [21-23]. Finally, the new model is very versatile and may therefore permit the study of various effects and phenomena, including dynamic stall effects, flow curvature effects, pitching circulation, added mass effects, interference among blades, and vibration effects.

\subsection{Method: The Mechanical-Electrical Analogy Approach}

Analogies are of greatest use in electromechanical systems when there is a connection between mechanical and electrical parts, especially when the system includes transducers between different energy domains, such as WECS.

Mechanical-electrical analogies are used to represent the function of a mechanical system as an equivalent electrical system by drawing analogies between mechanical and electrical parameters. The main value of analogies lies in the way in which mathematics unifies these diverse fields of engineering into one subject. Tools previously developed for solving problems in one field can be used to solve problems in another field. This is an important concept because some fields, particularly electrical engineering, have developed rich sets of problem-solving tools that are fully applicable to other engineering fields [24]; for example, there are simple and straightforward analogies between electrical and mechanical systems. Furthermore, analogies between mechanical systems and electrical or fluid systems are effective and commonly used.

Two valid techniques for modelling mechanical systems with electrical systems or for drawing analogies between the two types of systems can be found in the literature, and each method has its own advantages and disadvantages [25-28]. The first technique is intuitive; in this technique, current corresponds to velocity (both consist of motion), and voltage corresponds to force (both provide a "push"). The second technique is the through/across analogy that uses voltage as an analogy for velocity and current as an analogy for force. The two schools of thought for modelling mechanical systems with electrical systems are presented in Table 1 . Although both are valid, the through/across analogy results in a counterintuitive definition of impedance $[24,29,30]$. The universally applied analogy for impedance is that from the intuitive analogy listed in the corresponding section of Table 1. Therefore, the intuitive analogy is used in the present study. 
Table 1. System analogy used for developing the new model.

\begin{tabular}{|c|c|c|c|c|c|c|c|c|}
\hline \multicolumn{6}{|c|}{ Topology-Preserving Set (Book's Analogy) } & & & \\
\hline & & & \multicolumn{6}{|c|}{ Intuitive Analogy Set } \\
\hline \multicolumn{5}{|c|}{$\Longleftarrow \Longrightarrow$ Intuitive Stretch } & \multicolumn{2}{|c|}{$\Longleftarrow \Longrightarrow$ Topology Change } & & \\
\hline Description & Trans Mech & Rot Mech & Electrical & Thermal & Fluid & Trans Mech & Rot Mech & Description \\
\hline $\begin{array}{l}\text { "Through" } \\
\text { variable }\end{array}$ & $f$ (force) & $\tau$ (torque) & $i$ (current) & $\phi$ (heat flux) & $q($ flow $)$ & $v$ (velocity) & $\begin{array}{c}\omega \text { (angular } \\
\text { velocity) }\end{array}$ & Motion \\
\hline $\begin{array}{l}\text { "Across" } \\
\text { variable }\end{array}$ & $v$ (velocity) & $\begin{array}{l}\omega \text { (angular } \\
\text { velocity) }\end{array}$ & $v$ (voltage) & $T, \theta$ & $p$ (pressure) & $f$ (force) & $\tau$ (torque) & Push (force) \\
\hline $\begin{array}{l}\text { Dissipative } \\
\text { element }\end{array}$ & $v=\frac{1}{B} f$ & $\omega=\frac{1}{B_{r}} \tau$ & $v=i \boldsymbol{R}$ & $\theta=\phi \boldsymbol{R}$ & $p=q R$ & $f=v \boldsymbol{B}$ & $\tau=\omega B_{r}$ & $\begin{array}{l}\text { Dissipative } \\
\text { element }\end{array}$ \\
\hline Dissipation & $f^{2} \frac{1}{B}=\frac{v^{2}}{1 / B}$ & $\tau^{2} \frac{1}{B}=\frac{\omega^{2}}{1 / B}$ & $i^{2} \boldsymbol{R}=v^{2} / \boldsymbol{R}$ & $\mathrm{N} / \mathrm{A}$ & $q^{2} \boldsymbol{R}=p^{2} / \boldsymbol{R}$ & $v^{2} \boldsymbol{R}=f^{2} / \boldsymbol{R}$ & $\omega^{2} \boldsymbol{B}_{r}=\tau^{2} / \boldsymbol{B}_{r}$ & Dissipation \\
\hline $\begin{array}{l}\text { Through-variable } \\
\text { storage element }\end{array}$ & $\begin{array}{l}v=\frac{1}{K} \frac{d f}{d t} \text { or } \\
\int v d t=\frac{1}{R} f\end{array}$ & $\begin{array}{l}\omega=\frac{1}{K_{r}} \frac{d \tau}{d t} \text { or } \\
\int \omega d t=\frac{1}{K_{r}} \tau\end{array}$ & $v=L \frac{d i}{d t}$ & $\mathrm{~N} / \mathrm{A}$ & $p=I \frac{d q}{d t}$ & $\begin{array}{c}f=M \frac{d v}{d t} \\
\text { (one end must } \\
\text { be "grounded") }\end{array}$ & $\begin{array}{c}\tau=J \frac{d \omega}{d t} \\
\text { (one end must } \\
\text { be "grounded") }\end{array}$ & $\begin{array}{l}\text { Motion storage } \\
\text { element }\end{array}$ \\
\hline Energy & $E=\frac{1}{2} \frac{1}{K} f^{2}$ & $E=\frac{1}{2} \frac{1}{K_{r}} \tau^{2}$ & $E=\frac{1}{2} \mathbf{L} i^{2}$ & & $E=\frac{1}{2} I q^{2}$ & $E=\frac{1}{2} \boldsymbol{M} v^{2}$ & $E=\frac{1}{2} J \omega^{2}$ & Energy \\
\hline Impedance & $\begin{array}{r}\text { Standard d } \\
\text { shown to }\end{array}$ & $\begin{array}{l}\text { finition is } \\
\text { he right }\end{array}$ & $V(s)=I(s) \boldsymbol{L} s$ & & $P(s)=Q(s) \boldsymbol{I} s$ & $F(s)=V(s) \boldsymbol{M s}$ & $T(s)=\Omega(s) J s$ & Impedance \\
\hline $\begin{array}{l}\text { Across-variable } \\
\text { storage element }\end{array}$ & $\begin{array}{c}f=M \frac{d v}{d t} \\
\text { (one end must } \\
\text { be "grounded") }\end{array}$ & $\tau=J \frac{d \omega}{d t}$ & $i=C \frac{d v}{d t}$ & $\begin{array}{c}\phi=C \frac{d \theta}{d t} \\
\text { (one end must } \\
\text { be "grounded") }\end{array}$ & $\begin{array}{c}q=C \frac{d p}{d t} \text { (one end } \\
\text { is usually } \\
\text { "grounded") }\end{array}$ & $\begin{array}{l}v=\frac{1}{K} \frac{d f}{d t} \text { or } \\
\int v d t=\frac{1}{K} f\end{array}$ & $\begin{array}{l}\omega=\frac{1}{K_{r}} \frac{d \tau}{d t} \text { or } \\
\int \omega d t=\frac{1}{K_{r}} \tau\end{array}$ & $\begin{array}{l}\text { Push (force) } \\
\text { storage element }\end{array}$ \\
\hline Energy & $E=\frac{1}{2} \boldsymbol{M} v^{2}$ & $E=\frac{1}{2} J \omega^{2}$ & $E=\frac{1}{2} C v^{2}$ & $\begin{array}{c}E=C T(\text { not } \\
\text { analogous })\end{array}$ & $E=\frac{1}{2} C p^{2}$ & $E=\frac{1}{2} \frac{1}{K} f^{2}$ & $E=\frac{1}{2} \frac{1}{K_{r}} \tau^{2}$ & Energy \\
\hline Impedance & $\begin{array}{r}\text { The standard } \\
\text { mechanical impe } \\
\text { on the right, } \\
\text { intuitive }\end{array}$ & $\begin{array}{l}\text { lefinition of } \\
\text { lance is the one } \\
\text { ased on the } \\
\text { inalogy }\end{array}$ & $V(s)=I(s) \frac{I}{s C}$ & $\Theta(s)=\Phi(s) \frac{1}{s C}$ & $P(s)=Q(s) \frac{1}{s C}$ & $F(s)=V(s) \frac{K}{s}$ & $T(s)=\Omega(s) \frac{\boldsymbol{K}_{r}}{s}$ & Impedance \\
\hline
\end{tabular}




\section{Model Construction}

\subsection{Theoretical Background}

DT-VAWTs are lift-based machines, i.e., their driving torque is mainly generated by the lift force, and they consist of two or more aerofoil-shaped blades attached to a rotating vertical shaft. The interaction between the wind and the rotating blades creates a system of lift and drag forces over the blades themselves. The instantaneous resultant of these forces is dominated by the lift effect that is responsible for the aerodynamically generated mechanical torque. If we consider a Darrieus-type VAWT, as shown in Figure 2, the aerofoil blade is characterized by the height $2 H$, the rotor radius $R$, the number of blades $N_{\mathrm{b}}=3$ and the blade chord $c$. For a given point on any of the blades, $r$ and $z$ are the local radius and height, respectively. When the rotor is subject to an instantaneous incoming wind speed $W_{0}(t)$, it turns at a rotational speed $\omega(t)$.

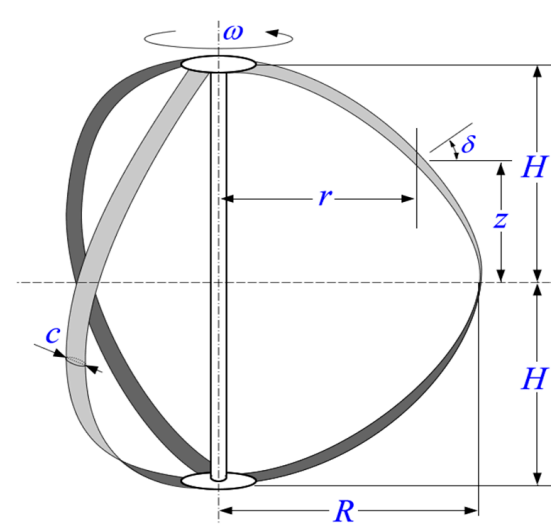

Figure 2. Schematic of a curved, three-blade DT-VAWT.

Figure 3 shows the aerodynamic forces and the three velocity vectors acting on DT-VAWT blade elements at a random position [31,32]. $F_{L}$ and $F_{D}$ are the lift and drag force, respectively. As the blade rotates, the local angle of attack $\alpha$ varies with the relative velocity $W_{\mathrm{r}}$. The incoming wind speed $W_{0}$ and the rotational velocity of the blade $\omega$ govern the orientation and magnitude of $W_{\mathrm{r}}[33,34]$. In turn, the forces $F_{L}$ and $F_{D}$ acting on the blade vary. The magnitude and orientation of the lift and drag forces vary along with the resultant force. The resultant force can be decomposed into a normal force $F_{N}$ and a tangential force $F_{\mathrm{T}}$. The tangential force component drives the rotation of the wind turbine and produces the torque necessary to generate electricity [35].

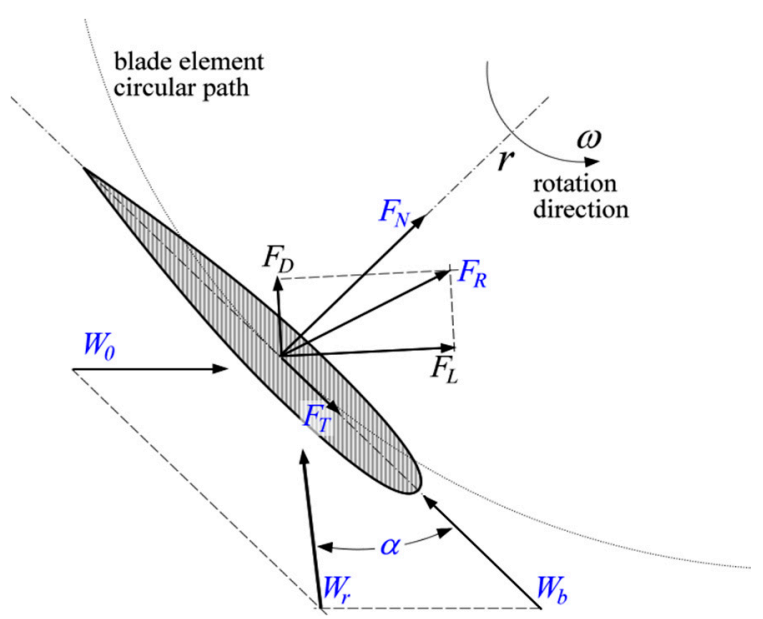

Figure 3. Velocity and force components for a DT-VAWT. 
A new approach for modelling DT-VAWT rotors using the electric-mechanic analogy was presented in [12-14]. These works provide a proof-of-concept demonstration of the approach and verify the feasibility of such a model through step-by-step demonstrations of the theoretical and practical concepts that underpin the new model as well as simulations and cross-validation of a single-blade model.

\subsubsection{Wind Flow as a Current Source}

As stated in $[12,14]$, an analogy can be made between the wind flow in a streamtube and an electric current. If the incident wind flow is assumed to be an electric current, then the wind's relative dynamic pressure flow can be defined as $q=\frac{1}{2} \rho W_{r b}^{2}$ (where $q$ is given in $N / m^{2}$ and the fluid density $\rho$ is given in $\mathrm{kg} / \mathrm{m}^{3}$ ), which is the energy of the wind due to its velocity, that can be considered an electric energy source. Thus, the instantaneous expression of the current source that represents the relative wind seen by the blade is as follows:

$$
i_{w}(t)=\left\{\begin{array}{l}
\Psi^{u} \sin (\omega t+2 \alpha) \text { for }-\pi / 2 \leq \theta \leq \pi / 2 \\
\Psi^{d} \sin (\omega t+2 \alpha) \text { for } 3 \pi / 2 \leq \theta \leq-\pi / 2
\end{array}\right.
$$

where $\Psi=\frac{1}{2} \rho W_{0}^{2}\left(\left(\frac{\omega R}{W_{0}}+\sin \theta_{b}\right)^{2}+\left(\cos \theta_{b}\right)^{2}(\cos \eta)^{2}\right)$ and $\alpha=\tan ^{-1}\left(\frac{\cos \theta_{b} \cos \eta}{\lambda_{i}+\sin \theta_{b}}\right)+\delta$.

$\Psi$ is the modulus of the current flow that varies with the rotational angle of the blade. For the Double-multiple multi-streamtube model shown in Figure 4, the modulus of the corresponding current in the downwind disk is slightly lower than that in the upwind disk $\left(\Psi^{d} \prec \Psi^{u}\right)$.
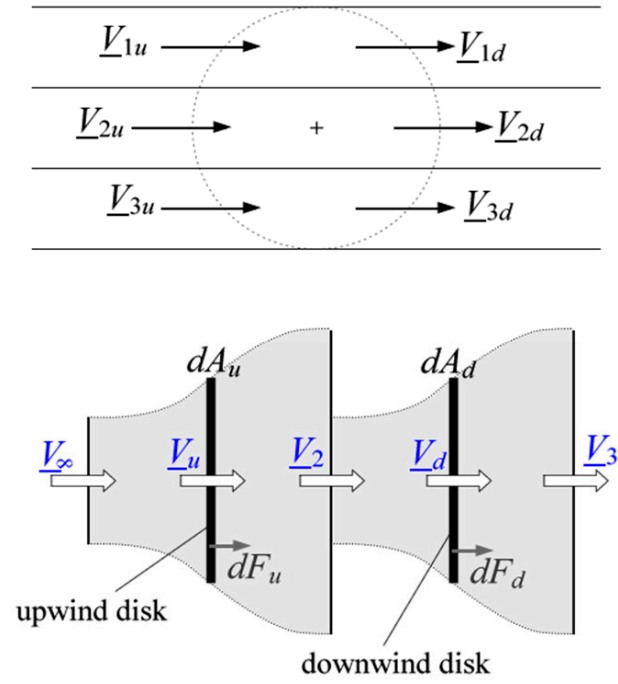

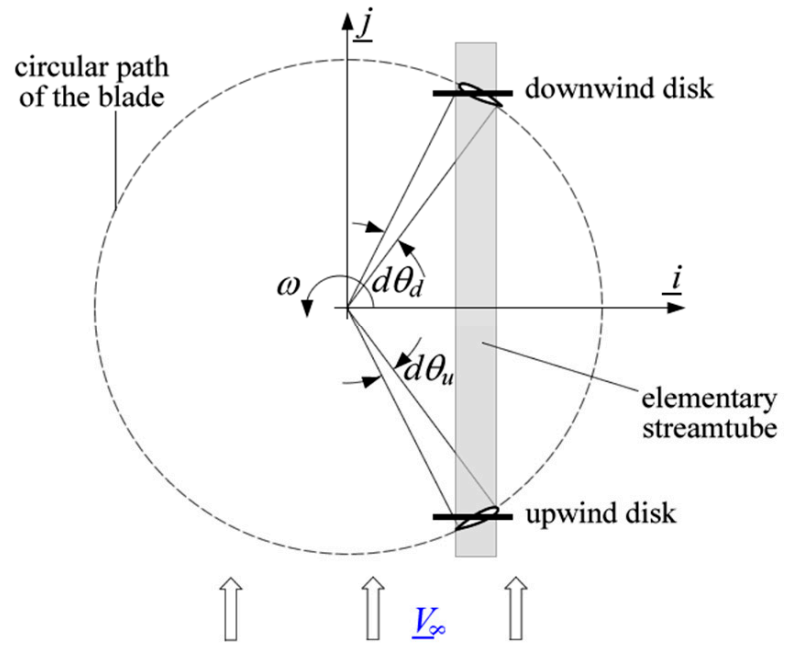

Figure 4. Double-multiple multi-streamtube model.

As described in $[12,14]$, the airflow in a streamtube can be compared to wind flow on a thin flat disc that is parallel to the airstream. In such conditions, the resistance to the airflow due to air friction on both sides of the plate is minimal, and the wind driving pressure difference from one point of the streamtube to another is approximately zero. Thus, the resistance to wind flow is zero, meaning that the electric resistance parallel to the current source tends to infinity such that the total current produced by the current generator flows in the blade. The improved equivalent electric model for wind flow in a double-multiple multi-streamtube model is shown in Figure 5. 


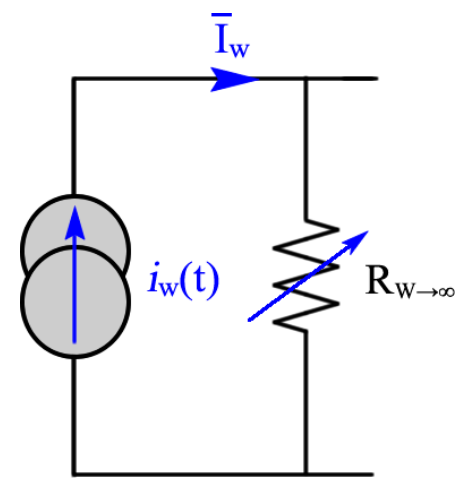

Figure 5. Electric circuit model for wind flow.

\subsubsection{Electric Circuit Model for a Single Blade}

The aerodynamic force coefficients acting on a cross-sectional blade element of a Darrieus wind turbine are shown in Figure 6. The directions of the lift and drag coefficients as well as their normal and tangential components are illustrated in this figure. The effort variable is voltage, while the flow variable is electrical current. The ratio of voltage to current is the electrical resistance (Ohm's law). The ratio of the effort variable to the flow variable in other domains is also described as resistance. Oscillating voltages and currents with a phase difference between them provide the concept of electrical impedance. Impedance can be considered an extension to the concept of resistance: resistance is associated with energy dissipation, while impedance encompasses both energy storage and energy dissipation.

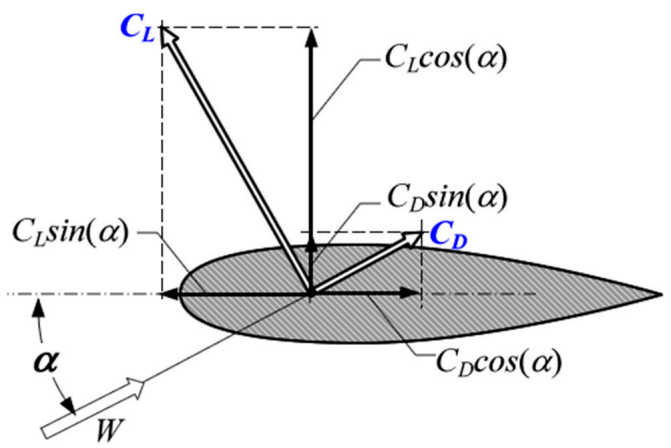

Figure 6. Aerodynamic coefficients acting on a Darrieus wind turbine blade element [36].

We consider a complex coordinate system as shown in Figure 6, where the vertical axis is assumed to be real and the horizontal axis is assumed to be imaginary. Then, the lift and drag coefficients can be written as follows:

$$
\left(\begin{array}{l}
\bar{C}_{L} \\
\bar{C}_{D}
\end{array}\right)=\left(\begin{array}{l}
C_{L} \cos \varphi+j C_{L} \frac{\sin \varphi}{\cos \eta} \\
C_{D} \sin \varphi-j C_{D} \frac{\cos \varphi}{\cos \eta}
\end{array}\right)
$$

The total impedance for a blade element is obtained by adding the elementary lift and drag impedances. We can then write:

$$
\bar{Z}_{B}=R_{B}+j X_{B}=Z_{N}+j Z_{T}
$$

where

$$
\left(\begin{array}{c}
\mathrm{Z}_{\mathrm{N}} \\
\mathrm{Z}_{\mathrm{T}}
\end{array}\right)=\left(\begin{array}{c}
R_{\mathrm{B}} \\
\mathrm{X}_{\mathrm{B}}
\end{array}\right)=\left(\begin{array}{c}
R_{\mathrm{L}}+R_{\mathrm{D}} \\
\mathrm{X}_{\mathrm{L}}-\mathrm{X}_{\mathrm{D}}
\end{array}\right)
$$


and

$$
\left(\begin{array}{l}
R_{\mathrm{L}} \\
R_{\mathrm{D}} \\
X_{\mathrm{L}} \\
X_{\mathrm{D}}
\end{array}\right)=\left(\begin{array}{c}
\sum_{i=1}^{n} c_{i} z_{i} C_{\mathrm{L} i} \cos \varphi_{i} \\
\sum_{i=1}^{n} c_{i} z_{i} C_{\mathrm{D} i} \sin \varphi_{i} \\
\sum_{i=1}^{n} c_{i} z_{i} C_{\mathrm{L} i} \frac{\sin \varphi_{i}}{\cos \eta_{i}} \\
\sum_{i=1}^{n} c_{i} z_{i} C_{\mathrm{D} i} \frac{\cos \varphi_{i}}{\cos \eta_{i}}
\end{array}\right)
$$

where $R_{L i}$ and $X_{L i}$ are the resistive and inductive components of the lift impedance, respectively, while $R_{\mathrm{D} i}$ and $X_{\mathrm{D} i}$ are the resistive and inductive components of the elementary drag impedance, respectively. Because $C_{L i}$ varies with the angle of attack $\alpha, R_{L i}$ and $X_{L i}$ correspond to a variable resistor $\left(R_{\mathrm{L} i}=f\left(\alpha_{i}\right)\right)$ and a variable inductor $\left(X_{\mathrm{L} i}=f\left(\alpha_{i}\right)\right)$, respectively. Similarly, because $C_{\mathrm{D} i}$ varies with the angle of attack $\alpha, R_{\mathrm{D} i}$ and $X_{\mathrm{D} i}$ correspond to a variable resistor $\left(R_{\mathrm{D} i}=f\left(\alpha_{i}\right)\right)$ and a variable capacitor $\left(X_{\mathrm{D} i}=f\left(\alpha_{i}\right)\right)$, respectively.

Figure 7 shows the enhanced equivalent electric model of a single blade. The normal and tangential voltages produced by the blade can be expressed as follows:

$$
\left(\begin{array}{c}
\bar{V}_{\mathrm{N}} \\
\bar{V}_{\mathrm{T}}
\end{array}\right)=\left(\begin{array}{c}
\bar{Z}_{\mathrm{N}} \bar{I}_{\mathrm{w}} \\
\bar{Z}_{\mathrm{T}} \bar{I}_{\mathrm{W}}
\end{array}\right)=\left(\begin{array}{c}
R_{\mathrm{B}} \mathrm{e}^{i 0} \\
X_{\mathrm{B}} \mathrm{e}^{i \pi / 2}
\end{array}\right)(\Psi \angle 2 \alpha, \Psi \angle 2 \alpha)=\left(\begin{array}{c}
\Psi R_{\mathrm{B}} \angle 2 \alpha \\
\Psi X_{\mathrm{B}} \angle 2 \alpha+\frac{\pi}{2}
\end{array}\right)
$$

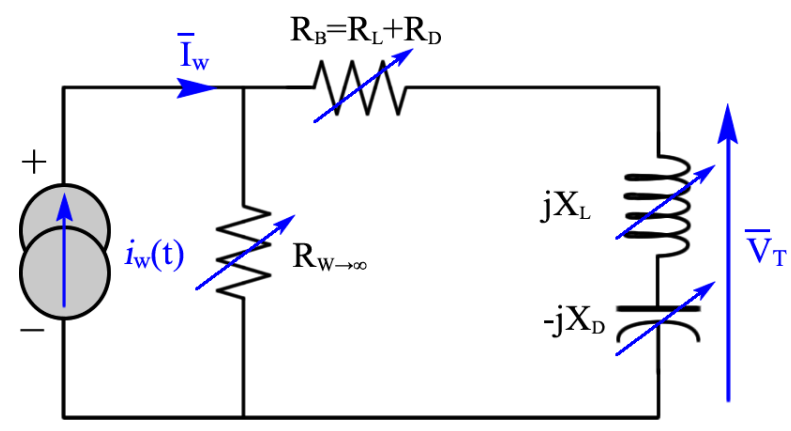

Figure 7. Electric circuit model for a single blade.

The variation of the lift, drag and normal resistances as well as those of the lift, drag and tangential reactances are shown in Figures 8 and 9, respectively [14]. These resistances and reactances are obtained considering a blade element; therefore, they are given per unit of blade height.

Following the laws of electrical circuit analysis, the branch with $R_{\mathrm{W} \rightarrow \infty}$ can be assumed to be an open circuit, and the total voltage across a blade can be obtained from the algebraic sum of the lift and drag voltages. We can then write:

$$
\bar{V}_{\mathrm{B}}=\bar{I}_{\mathrm{w}} \times \bar{Z}_{\mathrm{B}}=\bar{I}_{\mathrm{w}} \times\left(\bar{Z}_{\mathrm{N}}+j \bar{Z}_{\mathrm{T}}\right)=\bar{V}_{\mathrm{N}}+\bar{V}_{\mathrm{T}}
$$

When the blade is turning, the elementary work (or elementary amount of mechanical energy) is produced when an elementary force is exerted on an elementary linear distance $r d \theta$ covered by the blade. Furthermore, because the torque varies with the azimuth angle of the blade, the torque produced by a blade element is obtained by integrating with respect to the rotational angle. Then, the total torque produced by the entire blade for a complete revolution of the turbine is obtained by adding $\mathrm{n}$ discrete elementary torques over the full height of the rotor:

$$
T_{B}=\sum_{i=1}^{n} T_{B i}=\sum_{i=1}^{n}\left(\frac{r_{i}}{2 \pi} \int_{0}^{2 \pi} \Psi X_{B i} d \theta\right)=\frac{1}{2 \pi} \int_{0}^{2 \pi}\left(\sum_{i=1}^{n} r_{i} \Psi X_{B i}\right) d \theta
$$


The final expression of the total torque is then obtained;

$$
T_{B}=\frac{1}{2 \pi} \int_{0}^{2 \pi} \Psi\left(\sum_{i=1}^{n} r_{i} c_{i} z_{i}\left(C_{L i} \frac{\sin \varphi_{i}}{\cos \eta_{i}}-C_{D i} \frac{\cos \varphi_{i}}{\cos \eta_{i}}\right)\right) d \theta
$$

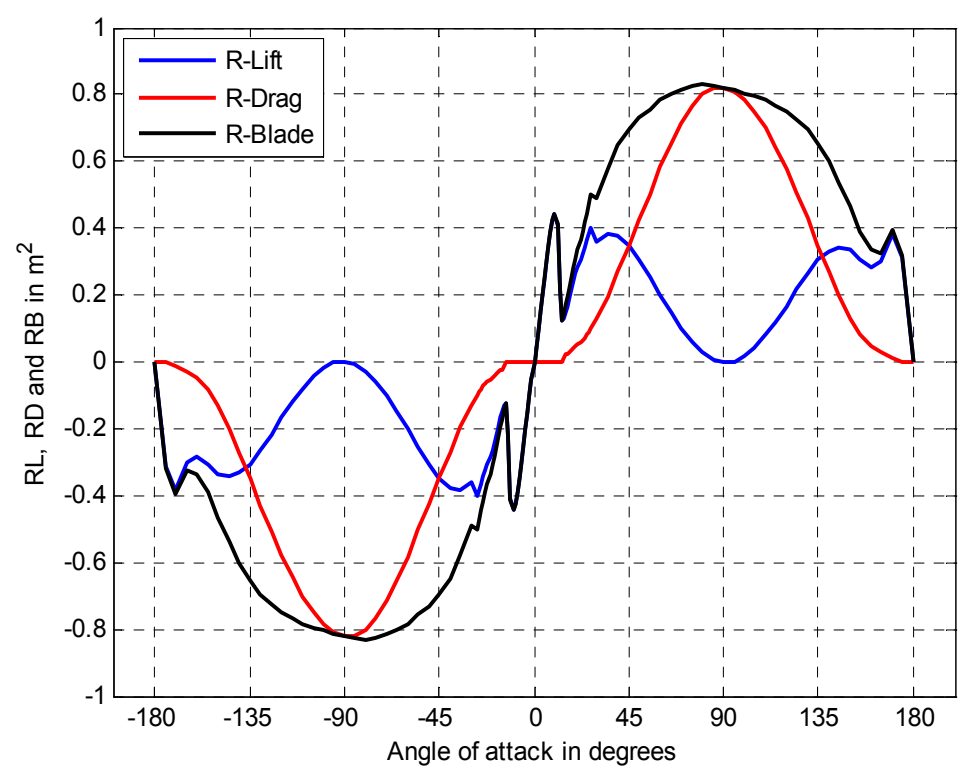

Figure 8. Lift, drag and normal resistance variations as functions of the angle of attack.

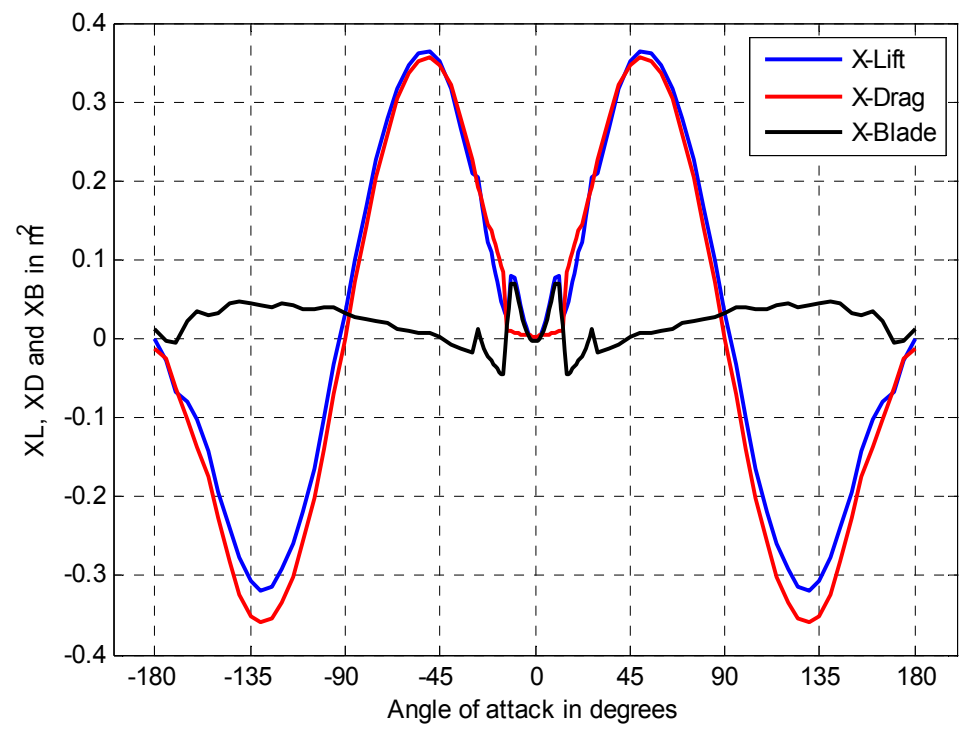

Figure 9. Lift, drag and tangential reactance variations as functions of the angle of attack.

\subsection{Electric Circuit Model for the Blades' Mechanical Coupling to the Shaft}

The wind turbine shaft is connected to the centre of the rotor; this shaft supports the rotor (hub and blades) and transmits the rotary motion and torque moments of the rotor to the gearbox and/or generator. When the rotor spins, the shaft spins as well. In this way, the rotor transfers its rotational mechanical energy to the shaft and then to an electrical generator on the other end. If we assume that the rotor's mechanical coupling to the shaft is ideal, then it would be electrically equivalent 
to an ideal transformer. Figure 10 shows the equivalent electric diagram for a single blade coupled to the shaft.

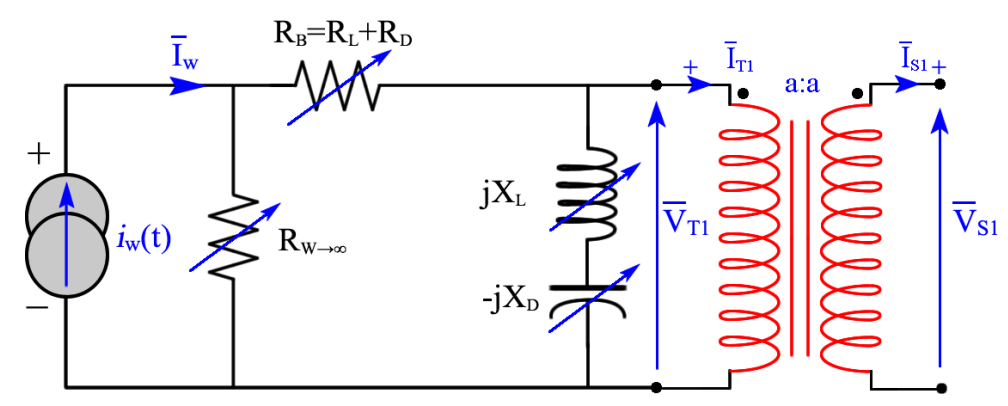

Figure 10. Equivalent diagram for a single blade coupled to the shaft.

At this stage of the WECS (shaft), we no longer consider fluid mechanics; instead, we address translation and/or rotation mechanics. Assuming an ideal autotransformer, the voltage at the primary side is equal to that at the secondary side, i.e., $V_{S i}=V_{T i}$. The current produced by the source corresponds to the relative wind seen by the blades at any moment. That is, for each blade:

$$
\begin{gathered}
\bar{I}_{B}=\bar{I}_{w}=\frac{1}{2} \rho V_{0}^{2}\left(\left(\frac{\omega R}{V_{0}}+\sin \theta_{b}\right)^{2}+\left(\cos \theta_{b}\right)^{2}(\cos \eta)^{2}\right) e^{j 2(\varphi+\delta)} \\
\bar{I}_{B}=\Psi e^{j 2 \alpha}
\end{gathered}
$$

where $\Psi=\frac{1}{2} \rho W_{0}^{2}\left(\left(\frac{\omega R}{W_{0}}+\sin \theta_{b}\right)^{2}+\left(\cos \theta_{b}\right)^{2}(\cos \eta)^{2}\right)$ and $\alpha=\tan ^{-1}\left(\frac{\cos \theta_{b} \cos \eta}{\lambda_{i}+\sin \theta_{b}}\right)+\delta$.

We can then obtain:

$$
\bar{V}_{T}=\Psi X_{\mathrm{B}} e^{i(2 \alpha+\pi / 2)} .
$$

Because the mechanical coupling of a single blade $i$ to the shaft can be modelled as an ideal autotransformer, we can then write:

$$
\left\{\begin{array}{c}
V_{T i}=V_{S i} \\
I_{T i}=I_{S i}
\end{array}\right.
$$

Assuming that the rotor mechanical coupling of three blades to the shaft is ideal, this coupling can be electrically modelled as multiple ideal primary transformers, as shown in Figure 11.

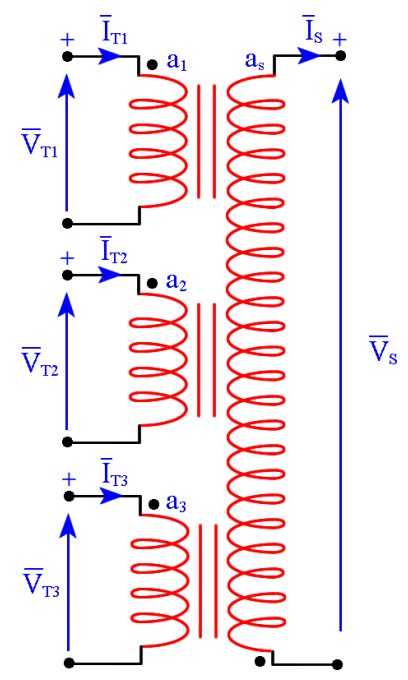

Figure 11. Rotor coupling of three blades modelled as an electric transformer. 
The windings of the corresponding transformer are made so that the following is true:

$$
\frac{V_{T 1}}{a_{1}}+\frac{V_{T 2}}{a_{2}}+\frac{V_{T 3}}{a_{3}}=\frac{V_{R}}{a_{R}}
$$

Because we have $a_{1}=a_{2}=a_{3}=a_{R}$, we can write:

$$
\vec{V}_{R}=\vec{V}_{T 1}+\vec{V}_{T 2}+\vec{V}_{T 3}
$$

The voltage at the secondary of the transformer can be obtained by vector addition of the three primary voltages because $\vec{V}_{T 1}, \vec{V}_{T 2}$ and $\vec{V}_{T 2}$ have variable moduli and phases while the phase difference from one blade to another remains constant. At any instant, the three voltages behave as if in an unbalanced three-phase system.

As suggested in the intuitive analogy, the rotational speed of the shaft $\omega$ is analogous to the electrical current. Finally, the rotational speed of the shaft can be assumed to be equivalent to the electric current at the secondary of the transformer, i.e., $I_{S}=\omega$. We can therefore write the following relations:

$$
\left\{\begin{array}{c}
I_{S}=I_{S 1}+I_{S 2}+I_{S 3}=\omega \\
I_{S 1}=I_{S 2}=I_{S 3}=\frac{\omega}{3}
\end{array}\right.
$$

\section{Results and Discussion}

\subsection{Electric Circuit Model for Three-Blade DT-VAWT Rotors: The Tchakoua Model}

We can now construct the equivalent electric model for the whole three-blade turbine. The equivalent circuits for various blades are brought together and are coupled based on the developments presented in Section 3. Figure 12 presents the Tchakoua model, which is the global equivalent electric model for a three-blade DT-VAWT.

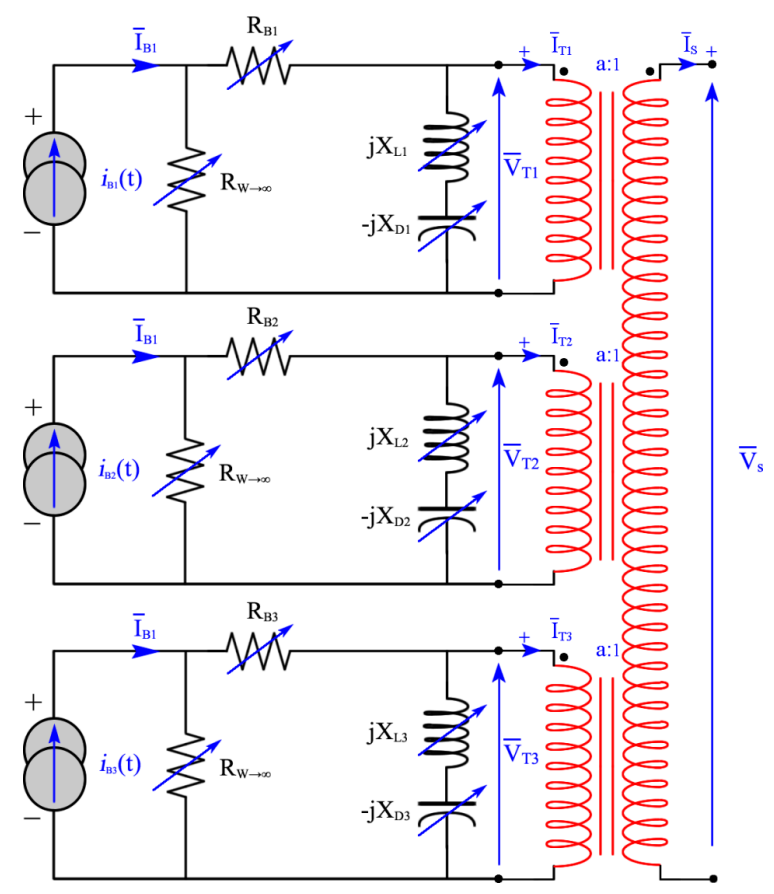

Figure 12. Equivalent electric diagram for a three-blade DT-VAWT.

Because the rotor has three blades, the angle between two blades is $\frac{2 \pi}{3}$. If we assume a constant wind flow, then the blades are subject to the same current vector with their respective phase delays. 
Assuming that the rotor turns in the forward rotational direction, we can write: $\left|\bar{I}_{B 1}\right|=\left|\bar{I}_{B 2}\right|=\left|\bar{I}_{B 3}\right|$; $\arg \left(\bar{I}_{B 2}\right)=\arg \left(\bar{I}_{B 1}\right)-\frac{2 \pi}{3}$ and $\arg \left(\bar{I}_{B 3}\right)=\arg \left(\bar{I}_{B 1}\right)+\frac{2 \pi}{3}$.

Then, the following matrix can be obtained:

$$
\left(\begin{array}{c}
\bar{V}_{B 1} \\
\bar{V}_{B 2} \\
\bar{V}_{B 3}
\end{array}\right)=\left(\operatorname{Im}\left(\begin{array}{ccc}
\bar{Z}_{B_{1}} & 0 & 0 \\
0 & \bar{Z}_{B_{2}} & 0 \\
0 & 0 & \bar{Z}_{B_{3}}
\end{array}\right)\right)\left(\begin{array}{c}
\bar{I}_{B 1} \\
\bar{I}_{B 2} \\
\bar{I}_{B 3}
\end{array}\right)
$$

Considering the operator $\bar{a}=1 \angle 120$, we have $\bar{I}_{B 2}=\bar{a}^{2} \cdot \bar{I}_{B 1}$ and $\bar{I}_{B 3}=\bar{a} \cdot \bar{I}_{B 1}$. Thus, the voltage vectors for the three-blade rotor can be written as follows:

$$
\begin{gathered}
\left(\begin{array}{c}
\bar{V}_{B 1} \\
\bar{V}_{B 2} \\
\bar{V}_{B 3}
\end{array}\right)=\left(\operatorname{Im}\left(\begin{array}{ccc}
\bar{Z}_{B_{1}} & 0 & 0 \\
0 & \bar{Z}_{B_{2}} & 0 \\
0 & 0 & \bar{Z}_{B_{3}}
\end{array}\right)\right)\left(\begin{array}{c}
1 \\
\bar{a}^{2} \\
\bar{a}
\end{array}\right) \bar{I}_{B 1} \\
\left(\begin{array}{c}
\bar{S}_{B 1} \\
\bar{S}_{B 2} \\
\bar{S}_{B 3}
\end{array}\right)=\left(\begin{array}{c}
\bar{V}_{B 1} \\
\bar{V}_{B 2} \\
\bar{V}_{B 3}
\end{array}\right) \times\left(\begin{array}{c}
\bar{I}_{S 1}^{*} \\
\bar{I}_{S 2}^{*} \\
\bar{I}_{S 3}^{*}
\end{array}\right)=\left(\begin{array}{c}
\bar{V}_{B 1} \\
\bar{V}_{B 2} \\
\bar{V}_{B 3}
\end{array}\right) \times\left(\begin{array}{c}
1 \\
\bar{a}^{2} \\
\bar{a}
\end{array}\right) \bar{I}_{S 1}^{*}
\end{gathered}
$$

Following Figure 4, the apparent power representing the contribution of the whole rotor to the shaft power can be obtained by adding the power produced by the three blades separately:

$$
\bar{S}_{T}=\bar{V}_{T} \bar{I}_{S}^{*}=\left(\bar{V}_{B 1}+\bar{V}_{B 1}+\bar{V}_{B 1}\right) \bar{I}_{S}^{*}
$$

Finally:

$$
\bar{S}_{T}=\left(\bar{Z}_{B_{1}}+\bar{Z}_{B_{2}} \bar{a}^{2}+\bar{Z}_{B_{3}} \bar{a}\right)\left|\bar{I}_{S}\right|^{2}
$$

The voltage produced by a sectional element of a single blade varies with its azimuth position and relative radius and height. The curved blade is discretized into $n$ blade elements, as suggested in [14], and the average power produced by a blade element for a complete revolution of the turbine is obtained by integrating the elementary power with respect to $\theta$.

$$
S_{B}=\frac{1}{2 \pi} \int_{0}^{2 \pi} \bar{s}(\omega t) d(\omega t)
$$

For different blades, the blades elements at the same high will produce the same power. We can then write:

$$
S_{B}=S_{B 1}=S_{B 2}=S_{B 3}=\frac{1}{2 \pi} \int_{0}^{2 \pi}\left((r \omega)\left(X_{D}-X_{L}\right) \Psi\right) d \theta_{b}
$$

That is:

$$
S_{B}=\frac{1}{2 \pi} \int_{0}^{2 \pi}\left[(r \omega)\left(X_{D}-X_{L}\right)\left(\frac{1}{2} \rho W_{0}^{2}\left(\left(\frac{\omega R}{W_{0}}+\sin \theta_{b}\right)^{2}+\left(\cos \theta_{b}\right)^{2}(\cos \eta)^{2}\right)\right)\right] d \theta_{b}
$$

We then obtain:

$$
S_{B}=\frac{1}{2} \rho W_{0}^{2} \cdot \frac{r \omega}{2 \pi} \int_{0}^{2 \pi}\left[\left(X_{D_{i}}-X_{L_{i}}\right)\left(\left(\frac{\omega R}{W_{0}}+\sin \theta_{b}\right)^{2}+\left(\cos \theta_{b}\right)^{2}(\cos \eta)^{2}\right)\right] d \theta_{b}
$$

Finally, the total average power produced by sectional element of the rotor is obtained by adding the power from each of the three blades. 


$$
S_{T}=3 S_{B}=\frac{3}{2} \rho W_{0}^{2} \cdot \frac{r \omega}{2 \pi} \int_{0}^{2 \pi}\left[\left(X_{D_{i}}-X_{L_{i}}\right)\left(\left(\frac{\omega R}{W_{0}}+\sin \theta_{b}\right)^{2}+\left(\cos \theta_{b}\right)^{2}(\cos \eta)^{2}\right)\right] d \theta_{b}
$$

\subsection{Simulation Results}

This section presents the results of the Tchakoua model for a three-blade DT-VAWT. The simulations were performed in MATLAB using data for NACA0012 that was obtained from different literature sources [37-39] with Reynolds numbers ranging from 500,000 to approximately 750,000. We choose the NACA0012 blade profile because it is one of the most studied and most commonly used profiles [39] Finally, the simulation results were assessed using results from the literature [40].

The simulation characteristics of the rotor were taken from [34] and are presented in Table 2.

Table 2. Blade simulation characteristics.

\begin{tabular}{cc}
\hline Number of Blades & 3 \\
\hline Aerofoil section & NACA0012 \\
Blade's average Reynolds number & 40,000 \\
Aerofoil chord length & $9.14 \mathrm{~cm}$ \\
Rotor tip speed & $45.7 \mathrm{~cm} / \mathrm{s}$ \\
Tip speed ratio & 5 \\
Chord-to-radius ratio & 0.15 \\
\hline
\end{tabular}

\subsubsection{Simulation Results for Current Sources}

Figure 13 shows the current variations for each blade. These variations are similar to those of $\mathrm{AOA}$ as a function of the rotational angle of the blade. In addition, the incident current for a given blade is at a maximum when its AOA is at a maximum; similarly, the incident current is minimal or zero when the AOA is minimal or zero. Furthermore, the incident currents appear similar to the alternating current of a symmetric three-phase power supply system with the same frequency and voltage amplitudes relative to a common reference but with a phase difference that is one-third of the period.

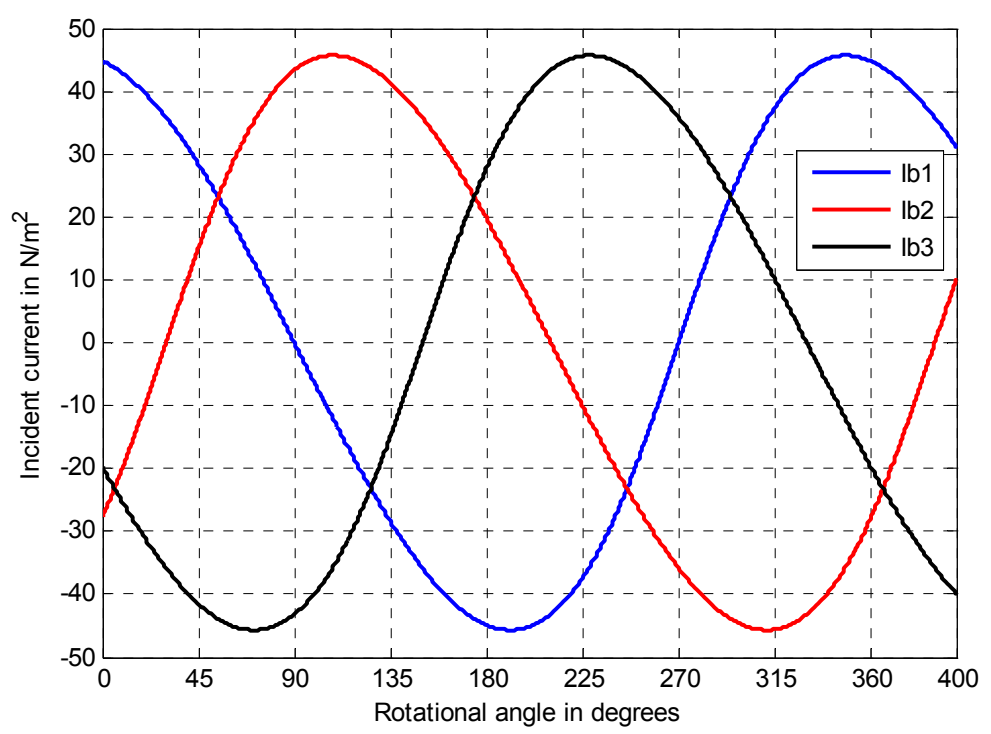

Figure 13. Incident current variations as functions of the rotational angle. 


\subsubsection{Variations of the Resistances and Reactances in the Model}

The total normal and resistive components of the blade impedance $R_{b}$ and the total tangential and reactive components of the blade impedance $X_{b}$ are plotted using the relations in Equations (4) and (5). Figures 14 and 15 show the variations of $R_{b}$ and $X_{b}$ for the three blades as functions of the rotational angle.

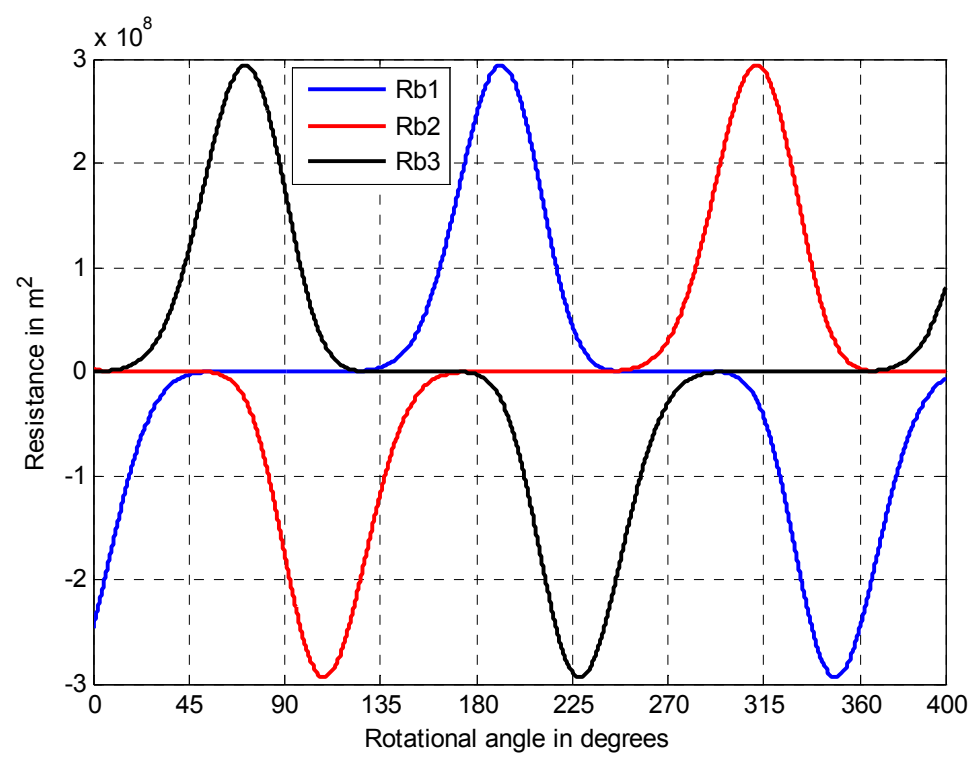

Figure 14. Variations of the blade total resistance as a function of the rotational angle.

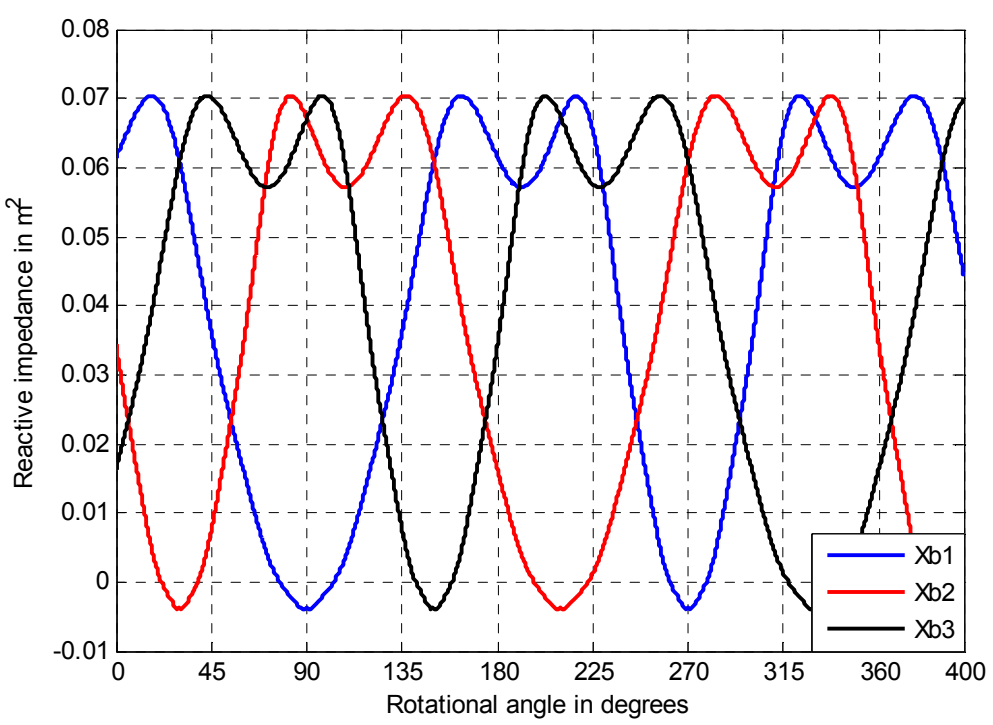

Figure 15. Variations of the blade reactance as a function of the rotational angle.

For a given blade, the resistance is zero when the blade rotational angle corresponds to wind incident angle equal to zero, that is a shortly before $\theta=\frac{\pi}{2}$ and $\theta=\frac{3 \pi}{2}$ for B1. At these positions, the blade is parallel to the wind flow streamtubes, and the incident angle is therefore zero. In addition, the blade's B1 resistance is at a maximum when corresponding wind incident angle is minims, which corresponds to a position close to $190^{\circ}$ from the reference point for these blade positions, the blades are perpendicular to the wind flow streamtubes, and the incident angle is at its maximum. Furthermore, the resistances vary between positive and negative quantities. According to our model inspired from 
double-multiple multi-streamtube models, the resistance of the blade to the wind flow is considered to be positive in the upwind disk and negative in the downwind disk.

The reactance of $\mathrm{B} 1$ is minimal when it is at $\theta=\frac{\pi}{2}$ and $\theta=\frac{3 \pi}{2}$. At these positions, the blade is parallel to the wind flow streamtubes, and the incident angle is therefore zero; thus, the contribution of the wind to the torque production is negligible. Starting from $\theta=\frac{\pi}{2}$, the blade reactance continue to increase reaching two maximums respectively at $160^{\circ}$ and $220^{\circ}$. At between $160^{\circ}$ and $220^{\circ}$, a valley appears that is caused by dynamic stall, which occurs when an aerofoil, operating in unsteady flow, overcomes the static stall angle. For a VAWT with a fixed blade geometry in unsteady flow and a given induction factor, the angle of attack is a function of the azimuth angle; for $\lambda<5$, the angle of attack can overcome the static stall angle, causing dynamic stall. During dynamic stall, large leading edge separated vortices are formed, delaying lift loss until they are convected over the surface results in a rapid decrease in lift.

\subsubsection{Variations of the Normal and Tangential Voltages}

Figures 16 and 17 plot the normal and tangential voltage variations as functions of the blade position, respectively.

The normal voltage produced by the blade during a complete rotation varies from zero to a minimal value. All the normal voltages are negative quantities at any instant of blade rotation because they stem from the drag coefficient and constitute obstructions to the blade rotation, meaning that they are negative contributions to the torque production. During a complete rotation of the reference blade, there are two minimums at rotational angles for which the angle of attack is zero at $190^{\circ}$ and $350^{\circ}$. The negative value of the resistance matches the contribution of this impedance element in the blade movement and thus in the torque production.

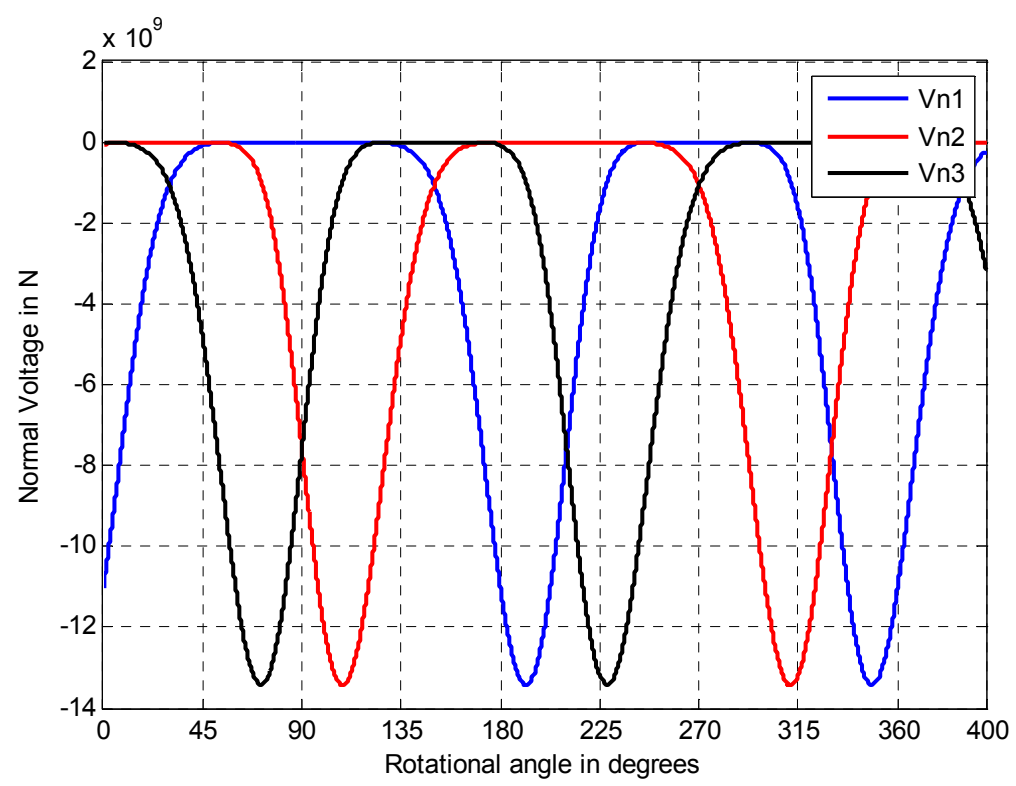

Figure 16. Normal voltage variations of the blade as a function of the rotational angle.

The tangential voltage produced by the blade during a complete rotation varies following an alternative and $2 \pi$ periodic signal. During a complete rotation of the blade, the tangential voltage is equal to zero at $\frac{\pi}{2}$ and $\frac{2 \pi}{3}$; these points are also inflexion points that correspond to angles for which the tangential impedance is zero. Similar to the tangential impedance, a valley occurs between $160^{\circ}$ and $220^{\circ}$ due to dynamic stall. The total voltage produced by the rotor is obtained by adding the voltages produced by the blades. As shown in Figure 17, the total voltage is an alternative and $\frac{2 \pi}{3}$ periodic signal is not equal to zero because at any moment, the blade voltage is an unbalanced three-phase 
system. The effect of dynamic stall can also be observed for the total voltage at $\frac{\pi}{2}$ and every $\frac{2 \pi}{3}$ after this point.

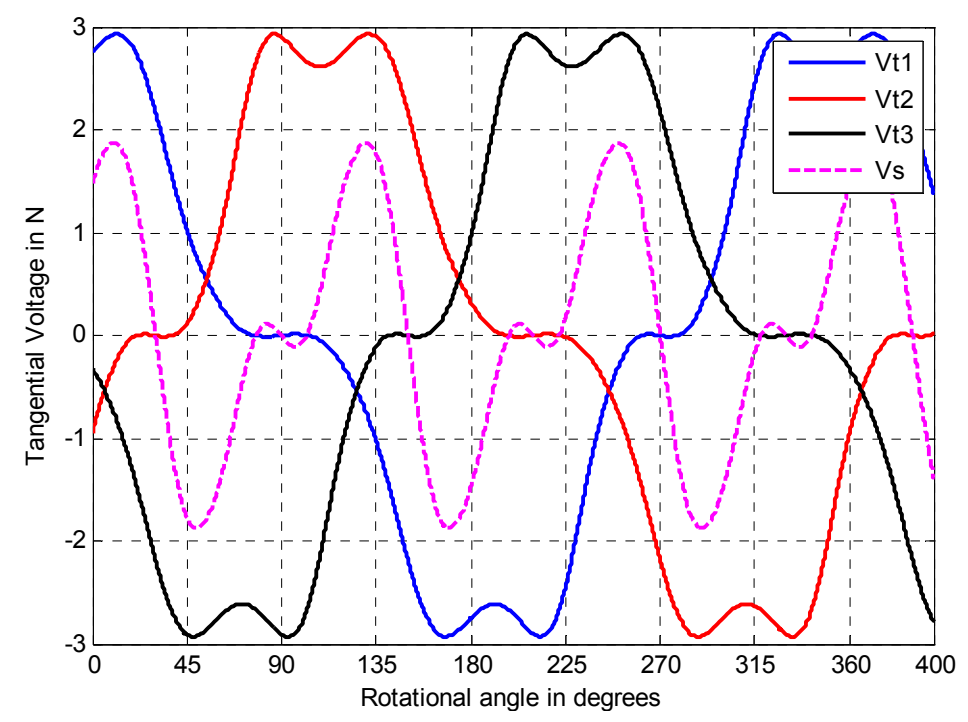

Figure 17. Tangential voltage variations of the blades as a function of the rotational angle.

\subsubsection{Power Variations Produced as a Function of the Rotational Angle}

The power produced by individual blades and the total power produced by the whole rotor are plotted in Figure 18. These results agree with findings in [32,35,41-43]. The power produced by each blade is always positive and is a variable and periodic quantity with a period of $\pi$. The power produced by a blade varies similar to the reactance with negative reactance producing positive power. A phase difference of $\frac{2 \pi}{3}$ exists between the powers of the three blades. The total power for the rotor is always a positive quantity; is variable and periodic with a period of $\frac{2 \pi}{3}$. The results obtained show strong agreement with results from both aerodynamic and CFD models in the literature.

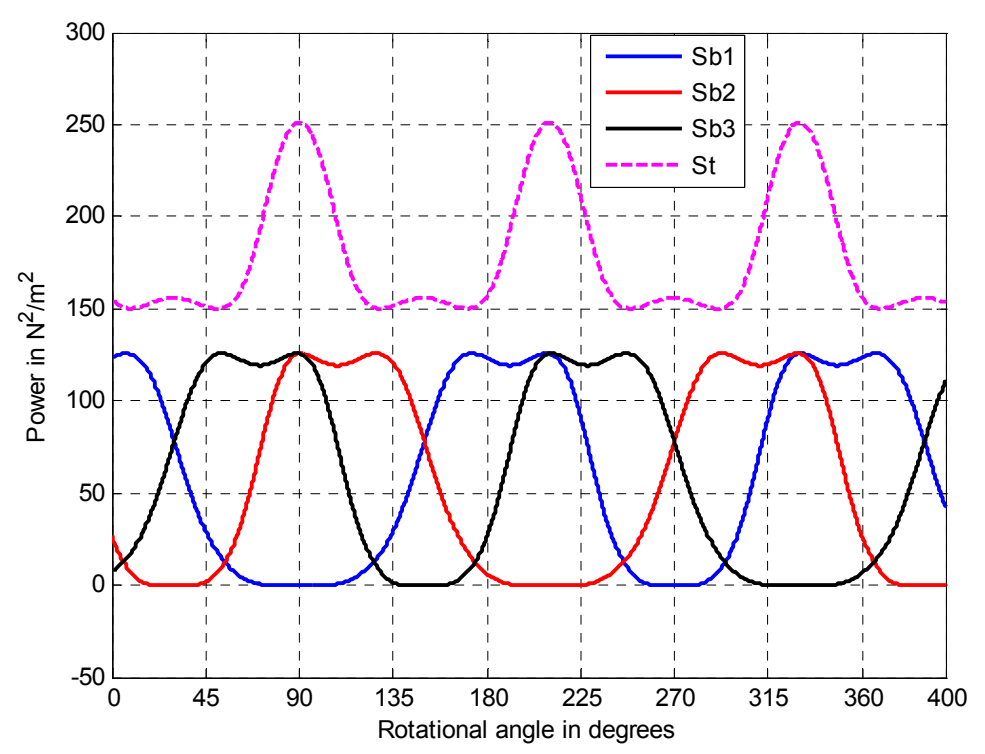

Figure 18. Power produced by the blades as a function of the rotational angle.

The normal and tangential voltages are both periodic values that undergo important variations during rotor rotation. The total tangential voltage produces the total torque. 


\section{Conclusions}

In this paper, an electric circuit model for a three-blade DT-VAWT rotor is proposed. The new Tchakoua model is based on a new approach for modelling DT-VAWT rotors using the mechanical-electrical analogy. Indeed, the construction of this novel model is further to the proof-of-concept demonstration of the relevancy of modelling VAWTs rotors using electrical equivalent circuit analogy that was performed in previous research work. The model is based on an analogy with the double multiple streamtube model and was obtained by combining the equivalent electrical models for the wind, the three blades and the mechanical coupling. For validation, simulations were conducted using MATLAB for a three-bladed rotor. Results obtained for models outputs such as voltages and power are consistent with findings of the Paraschivoiu double-multiple streamtube model as well as Frank Scheurich among others.

The Tchakoua model is more appropriate for the design, performance prediction and optimization of Darrieus rotors. Mechanical fault diagnosis and prognosis are also important because the model can be used to simulate rotor behaviour in the event of mechanical faults in one or more of the blades or in the rotor-shaft coupling elements. The model can also simulate turbine operation in the event of mechanical faults in one or more rotor elements. The simulations were conducted in MATLAB, and the results show high accuracy with the Paraschivoiu model as well as other results in the literature.

Despite the very simple design philosophy of VAWTs, their aerodynamics presents several challenges. The main feature of VAWTs is that the effective angle of attack "seen" by the blades undergoes a very large variation that in moderate to low tip speed conditions drives the blades into stall for both negative and the positive angles of attack. In future works, we intend to implement the Tchakoua model in simulation tools such as MATLAB Simulik or P-SPICE to study the effects of varying angles of attack within the post-stall region on flow unsteadiness and dynamic stall phenomena. The model could be extended to other types of wind turbines including horizontal axis wind turbines, Savonious-type VAWTs and hybrid Darrius-Savonius VAWTs. Additionally, the Tchakoua model will be used to study the influence of wind flow turbulence on turbine vibrations. Transitional (starting) and permanent sate functioning of VAWTs may also be examined. Finally, we intend to use the model to study the impact of structural faults in one or more blades on a DT-VAWT. As a long-term goal, the Tchakoua model will be linked to existing models of other electrical and mechanical wind turbine parts to obtain a global Darrieus-type WECS model.

Acknowledgments: The authors would like to thank the Natural Science and Engineering Research Council of Canada (NSERC) for financially supporting this research. The authors are also grateful to the editor and the four anonymous reviewers for their valuable comments and suggestions that improved the quality of this paper.

Author Contributions: Pierre Tchakoua is the main author of this work. This paper further elaborates on some of the results from his Ph.D. dissertation. René Wamkeue and Mohand Ouhrouche supervised the project and supported Pierre Tchakoua's research in terms of both scientific and technical expertise. Gabriel Ekemb and Ernesto Benini assisted in the results analysis and interpretation. The manuscript was written by Pierre Tchakoua and was reviewed and revised by René Wamkeue, Mohand Ouhrouche and Ernesto Benini.

Conflicts of Interest: The authors declare no conflicts of interest.

\section{Abbreviations}

$\begin{array}{ll}A_{\mathrm{e}} & \text { Area of a blade element } \\ c & \text { Chord of the blade }(\mathrm{m}) \\ C_{e q} & \text { Equivalent or total coefficient } \\ C_{L} & \text { Lift coefficient } \\ C_{D} & \text { Drag coefficient } \\ C_{N} & \text { Normal coefficient } \\ C_{T} & \text { Tangential coefficient } \\ C_{e q} & \text { Total or equivalent coefficient } \\ F_{N} & \text { Normal force }(\mathrm{N}) \\ F_{T} & \text { Tangential force }(\mathrm{N}) \\ F_{L} & \text { Lift force }(\mathrm{N}) \\ F_{D} & \text { Drag force }(\mathrm{N})\end{array}$




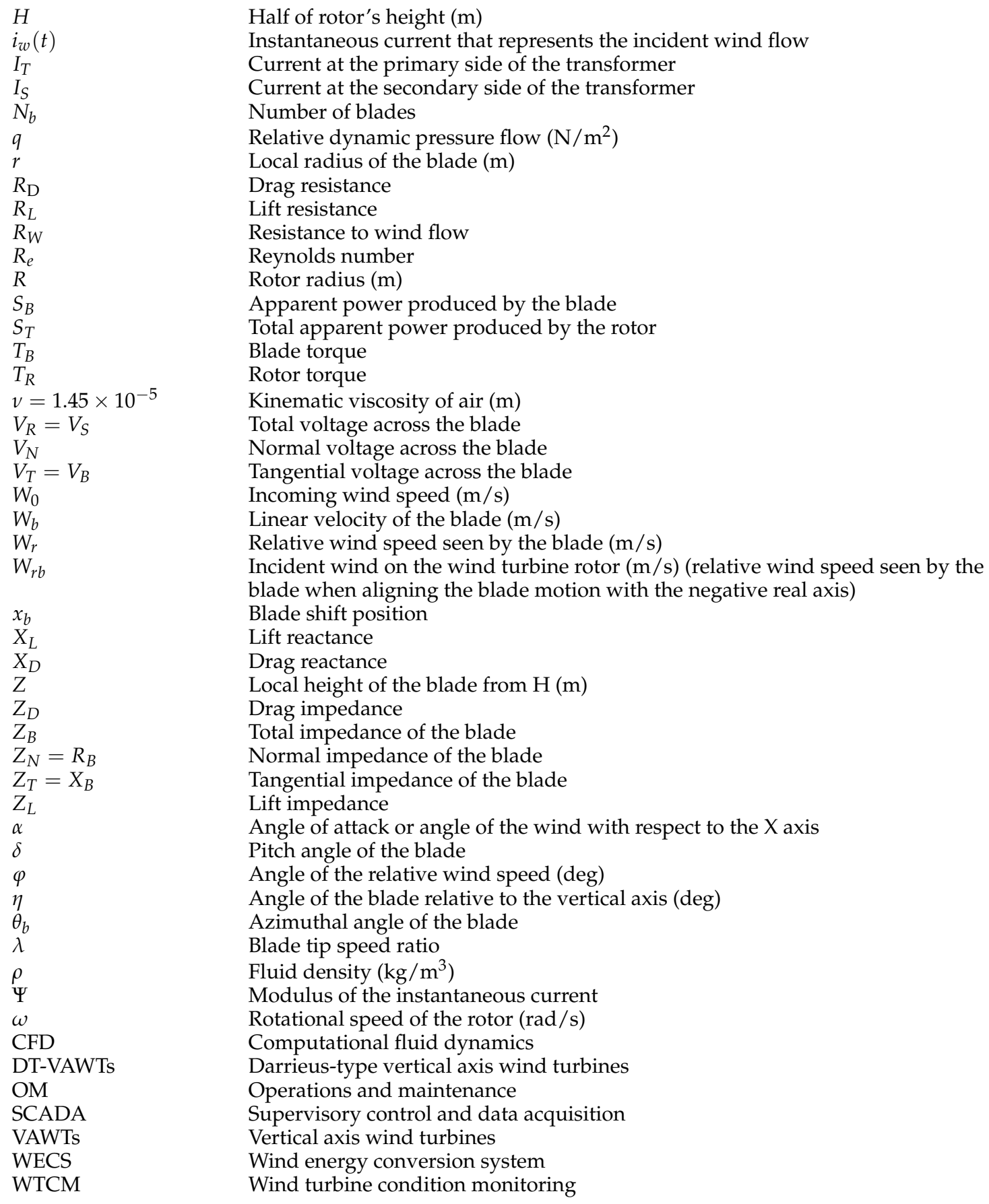

\section{References}

1. Tilmans, H.A. Equivalent circuit representation of electromechanical transducers: I. Lumped-parameter systems. J. Micromech. Microeng. 1996, 6, 157-176. [CrossRef]

2. Mason, W. An electromechanical representation of a piezoelectric crystal used as a transducer. Proc. Inst. Radio Eng. 1935, 23, 1252-1263.

3. Tilmans, H.A. Equivalent circuit representation of electromechanical transducers: II. Distributed-parameter systems. J. Micromech. Microeng. 1997, 7, 285-309. [CrossRef]

4. Barakati, S.M. Modeling and Controller Design of a Wind Energy Conversion System Including a Matrix Converter. Ph.D. Thesis, University of Waterloo, Waterloo, ON, Canada, 2008.

5. Kim, H.-W.; Kim, S.-S.; Ko, H.-S. Modeling and control of PMSG-based variable-speed wind turbine. Electr. Power Syst. Res. 2010, 80, 46-52. [CrossRef] 
6. Borowy, B.S.; Salameh, Z.M. Dynamic response of a stand-alone wind energy conversion system with battery energy storage to a wind gust. IEEE Trans. Energy Conve. 1997, 12, 73-78. [CrossRef]

7. Delarue, P.; Bouscayrol, A.; Tounzi, A.; Guillaud, X.; Lancigu, G. Modelling, control and simulation of an overall wind energy conversion system. Renew. Energy 2003, 28, 1169-1185. [CrossRef]

8. Slootweg, J.; Haan, S.D.; Polinder, H.; Kling, W. General model for representing variable speed wind turbines in power system dynamics simulations. IEEE Trans. Power Syst. 2003, 18, 144-151. [CrossRef]

9. Junyent-Ferré, A.; Gomis-Bellmunt, O.; Sumper, A.; Sala, M.; Mata, M. Modeling and control of the doubly fed induction generator wind turbine. Simul. Model. Pract. Theory 2010, 18, 1365-1381. [CrossRef]

10. Bolik, S.M. Modelling and Analysis of Variable Speed Wind Turbines with induction Generator during Grid Fault; Aalborg Universitet: Aalborg, Denmark, 2004.

11. Perdana, A. Dynamic Models of Wind Turbines; Chalmers University of Technology: Göteborg, Sweden, 2008.

12. Tchakoua, P.; Ouhrouche, M.; Tameghe, T.A.; Ekemb, G.; Wamkeue, R.; Slaoui-Hasnaoui, F. Basis of theoretical formulations for new approach for modelling darrieus-type vertical axis wind turbine rotors using electrical equivalent circuit analogy. In Proceedings of the 2015 IEEE 3rd International Renewable and Sustainable Energy Conference, Marrakech \& Ouarzazate, Morocco, 10-13 December 2015; pp. 1-7.

13. Tchakoua, P.; Ouhrouche, M.; Tameghe, T.A.; Ekemb, G.; Wamkeue, R.; Slaoui-Hasnaoui, F. Development of equivalent electric circuit model for darrieus-type vertical axis wind turbine rotor using mechanic-electric analogy approach. In Proceedings of the 2015 IEEE 3rd International Renewable and Sustainable Energy Conference, Marrakech \& Ouarzazate, Morocco, 10-13 December 2015; pp. 1-8.

14. Tchakoua, P.; Wamkeue, R.; Ouhrouche, M.; Tameghe, T.A.; Ekemb, G. A new approach for modeling Darrieus-type vertical axis wind turbine rotors using electrical equivalent circuit analogy: Basis of theoretical formulations and model development. Energies 2015, 8, 10684-10717. [CrossRef]

15. Eriksson, S.; Bernhoff, H.; Leijon, M. Evaluation of different turbine concepts for wind power. Renew. Sustain. Energy Rev. 2008, 12, 1419-1434. [CrossRef]

16. Tjiu, W.; Marnoto, T.; Mat, S.; Ruslan, M.H.; Sopian, K. Darrieus vertical axis wind turbine for power generation I: Assessment of Darrieus VAWT configurations. Renew. Energy 2015, 75, 50-67. [CrossRef]

17. Bedon, G.; Castelli, M.R.; Benini, E. Optimal spanwise chord and thickness distribution for a Troposkien Darrieus wind turbine. J. Wind Eng. Ind. Aerodyn. 2014, 125, 13-21. [CrossRef]

18. Tchakoua, P.; Wamkeue, R.; Tameghe, T.A.; Ekemb, G. A review of concepts and methods for wind turbines condition monitoring. In Proceedings of the 2013 IEEE World Congress on Computer and Information Technology (WCCIT), Sousse, Tunisia, 22-24 June 2013; pp. 1-9.

19. Tchakoua, P.; Wamkeue, R.; Slaoui-Hasnaoui, F.; Tameghe, T.A.; Ekemb, G. New trends and future challenges for wind turbines condition monitoring. In Proceedings of the 2013 IEEE International Conference on Control, Automation and Information Sciences (ICCAIS), Nha Trang, Vietnam, 25-28 November 2013; pp. 238-245.

20. Tchakoua, P.; Wamkeue, R.; Ouhrouche, M.; Slaoui-Hasnaoui, F.; Tameghe, T.A.; Ekemb, G. Wind turbine condition monitoring: State-of-the-art review, new trends, and future challenges. Energies 2014, 7, 2595-2630.

21. Yang, W.; Tavner, P.J.; Crabtree, C.J.; Wilkinson, M. Cost-effective condition monitoring for wind turbines. IEEE Trans. Ind. Electron. 2010, 57, 263-271. [CrossRef]

22. Yang, W.; Jiang, J.; Tavner, P.; Crabtree, C. Monitoring wind turbine condition by the approach of Empirical Mode Decomposition. In Proceedings of the 2008 International Conference on Electrical Machines and Systems (ICEMS), Wuhan, China, 17-20 October 2008; pp. 736-740.

23. Yang, W.; Tavner, P.; Crabtree, C.; Wilkinson, M. Research on a simple, cheap but globally effective condition monitoring technique for wind turbines. In Proceedings of the 2008 International Conference on Electrical Machines and Systems (ICEMS), Wuhan, China, 17-20 October 2008; pp. 1-5.

24. Lewis, J.W. Modeling Engineering Systems: PC-Based Techniques and Design Tools; High Text Publications: San Diego, CA, USA, 1994.

25. Hogan, N.; Breedveld, P. The physical basis of analogies in network models of physical system dynamics. Simul. Ser. 1999, 31, 96-104.

26. Olson, H.F. Dynamical Analogies; Van Nostrand: Princeton, NJ, USA, 1958.

27. Firestone, F. The mobility method of computing the vibration of linear mechanical and acoustical systems: Mechanical-electrical analogies. J. Appl. Phys. 1938, 9, 373-387. [CrossRef]

28. Calvo, J.A.; Alvarez-Caldas, C.; San, J.L. Analysis of Dynamic Systems Using Bond Graph Method through SIMULINK; InTech: Rijeka, Croatia, 2011. 
29. Firestone, F. A new analogy between mechanical and electrical systems. J. Acoust. Soc. Am. 1933, 4, $249-267$. [CrossRef]

30. Bishop, R.H. Mechatronics: An Introduction; CRC Press: Boca Raton, FL, USA, 2005.

31. Zhang, L.; Liang, Y.; Liu, X.; Jiao, Q.; Guo, J. Aerodynamic performance prediction of straight-bladed vertical axis wind turbine based on CFD. Adv. Mech. Eng. 2013, 5. [CrossRef]

32. Paraschivoiu, I. Wind Turbine Design: With Emphasis on Darrieus Concept; Presses Inter Polytechnique: Montreal, QC, Canada, 2002.

33. Islam, M.; Ting, D.S.-K.; Fartaj, A. Aerodynamic models for Darrieus-type straight-bladed vertical axis wind turbines. Renew. Sustain. Energy Rev. 2008, 12, 1087-1109. [CrossRef]

34. Scheurich, F.; Fletcher, T.M.; Brown, R.E. Simulating the aerodynamic performance and wake dynamics of a vertical-axis wind turbine. Wind Energy 2011, 14, 159-177. [CrossRef]

35. Beri, H.; Yao, Y. Double multiple streamtube model and numerical analysis of vertical axis wind turbine. Energy Power Eng. 2011, 3, 262-270. [CrossRef]

36. Claessens, M.C. The Design and Testing of Airfoils for Application in Small Vertical Axis Wind Turbines. Master's Thesis, Delft University of Technology, Delft, The Netherlands, 2006.

37. Sheldahl, R.E.; Klimas, P.C. Aerodynamic Characteristics of seven Symmetrical Airfoil Sections through 180-Degree Angle of Attack for Use in Aerodynamic Analysis of Vertical Axis Wind Turbines; Technical Report; Sandia National Labs: Albuquerque, NM, USA, 1981.

38. Critzos, C.C.; Heyson, H.H.; Boswinkle, R.W. Aerodynamic Characteristics of NACA 0012 Airfoil Section at Angles of Attack from 0 to 180 Degrees; National Advisory Committee for Aeronautics: Washington, DC, USA, 1955.

39. Miley, S.J. A Catalog of Low Reynolds Number Airfoil Data for Wind Turbine Applications; National Technical Information Service: Alexandria, VA, USA, 1982.

40. Timmer, W. Aerodynamic Characteristics of Wind Turbine Blade Airfoils at High Angles-of-Attack; European Wind Energy Association: Brussels, Belgium, 2010.

41. Li, S.; Li, Y. Numerical study on the performance effect of solidity on the straight-bladed vertical axis wind turbine. In Proceedings of the 2010 Asia-Pacific Power and Energy Engineering Conference (APPEEC), Chengdu, China, 28-31 March 2010; pp. 1-4.

42. Attia, E.; Saber, H.; Gamal, H.E. Analysis of straight bladed vertical axis wind turbine. Int. J. Eng. Res. Technol. 2015, 4. [CrossRef]

43. Scheurich, F.; Brown, R.E. Modelling the aerodynamics of vertical-axis wind turbines in unsteady wind conditions. Wind Energy 2013, 16, 91-107. [CrossRef] 